\title{
The EU and the Recycling of Colonialism: Formation of Europeans through intercultural dialogue
}

Robert Aman

\section{Linköping University Post Print}

N.B.: When citing this work, cite the original article.

This is the pre-reviewed version of the following article:

Robert Aman , The EU and the Recycling of Colonialism: Formation of Europeans through intercultural dialogue, 2012, Educational Philosophy and Theory, (), , .

which has been published in final form at:

http://dx.doi.org/10.1111/j.1469-5812.2011.00839.x

Copyright: Wiley-Blackwell http://eu.wiley.com/WileyCDA/Brand/id-35.html

Postprint available at: Linköping University Electronic Press

http://urn.kb.se/resolve?urn=urn:nbn:se:liu:diva-76574 


\title{
EU and the Recycling of Colonialism: Formation of Europeans through Intercultural Dialogue
}

\begin{abstract}
The present essay focuses on problematizing the European Union's claim that intercultural dialogue constitutes an advocated method of talking through cultural boundaries - inside as well as outside the classroom - based on mutual empathy and non-domination. More precisely, the aim is to analyze who is being constructed as counterparts of the intercultural dialogue through the discourse produced by the EU in policies on education, culture and intercultural dialogue. Within the Union, Europeans are portrayed as having an a priori historical existence, while the ones excluded from this notion are evoked to demonstrate its difference in comparison to the European one. The results show that subjects not considered as Europeans serve as markers of the multicultural present of the space. Thus, intercultural dialogue seems to consolidate differences between European and Other - the 'We' and 'Them' in the dialogue - rather than, as in line with its purpose, bringing subjects together.
\end{abstract}

\section{Introduction}

Let us begin by outlining intercultural dialogue as the essay's focal point, and then move over to reflect on how the counterparts of the dialogue are determined. The political debate in the European Union around the turn of millennium involved the idea that the solution to the challenges the supranational collaboration faced in terms of 'cultural diversity' or 'multiculturalism' was to be found in cross-cultural communication; referred to as intercultural dialogue. This policy term involves a series of strategies for talking through 'differences' and establishing dialogue based on mutual empathy for respective cultural belonging. 'We', the argument goes in official documents (cf. European Commission [EC], 2007), need to bound together around the features 'We' have in common; heritage, history, values etc; in short, the culture. Some scholars claim that the presence of intercultural dialogue in policy on culture has been growing at an exceptional rate (cf. Dahlén, 1997; Dewey, 2008) and focused their attention on the EU's work on promoting a coherent cultural identity among its citizens. Furthermore, the educational settings in the member states are outlined as fundamental pieces in the citizens' process of acquiring what is called 'intercultural competence' - the individual skills necessary for a citizen in a society characterized by intercultural dialogue and also made part of the objectives for 'Lifelong Learning' (EC, 2007; EC, 2001). Or to use the wording of the Commission (2009, p. 2):

[T] he primary goal of European cooperation should be to support the further development of education and training systems in the Member States which are aimed at promoting democratic values, social cohesion, active citizenship, and intercultural dialogue.

In conjunction with what is being put forward by the Commission, the idea that dialogue constitutes an advocated method to talk through cultural differences embraces the problem that this essay seeks to deal with: every dialogue requires actors engaging in the communication and in this particular case it is those embedded in the idea of 'We' - the rightful citizens of the Union - and its counterpart. There are no given traits, however, that turn a subject into 'French', 'Japanese' or, as in this case, 'European' - rather, it is a geopolitical construction recalling the well-known words of Massimo D'Azeglio: 'We have created Italy; now we need to create Italians' (cited in Hogan, 2004, p. 90). References to a 
certain people, population or national identity is made both inclusionary as well as exclusionary; including those regarded as part of the national unity and excluding the ones not considered as such. Although human communities and their impedimenta tend to generally claim to be rooted in the remotest of antiquity, the construction of a European people with a certain culture and identity is traced to the colonial endeavors - formed as an antithesis to that which is not Europe (Mignolo, 2006). Only through a confrontation with its colonial other, to polarize the distinction between European and Other - 'Us' and 'Them' - could Europe imagine and theorize its own identity and gain its strength. This was later formalized through the invention of 'citizenship' in the newly formed European nation-states to scatter the people - replacing communities of faith with communities of birth (Mignolo, 2006).

Bearing this in mind, the point is now being made - as seen in the preceding quotation that in various member states education plays a major part in the attempts to develop a sense of a European citizenship and intercultural competence among its population (cf. Alred et al., 2006; Osler \& Starkey, 2002; Wimberley, 2003). However, these kinds of studies are often driven to advertise a lofty Europe of i.e. democracy, tolerance and respect for other cultures, ignoring issues of power rather than problematizing assumptions about these matters (cf. Dainotto, 2007). This essay will thus provide a critical analysis of intercultural dialogue in relation to cultural identity in the EU. Put simply, my overarching aim is to investigate how the EU articulates a cultural identity for itself by attempts to impose an intercultural dialogue. From that perspective, I will relate the cultural identity politics at the policy level of the EU to its possible implications in the social terrain and educational sphere, evoking the issue of how a unified identity cannot be inclusionary without being exclusionary - constructing an 'Us' and 'Them' through the idea of dialogue. This merits serious scrutiny since it illustrates how the EU of today seek to grapple with issues of cultural diversity, remembering how, for instance, Germany's Angela Merkel, Great Britain's David Cameron or France's Nicolas Sarkozy, recently labeled multiculturalism an 'utter failure' (The Guardian, 2010).

The work to establish greater cohesion across national and cultural borders among the member states has been part of the European Community since the outset (Hansen, 2000a). This process intensified, however, during the nineties and witnessed three major changes in the political landscape: the disappearance of the Soviet bloc, Germany's reunification and the signing of the Maastricht Treaty (or Treaty on European Union) (Anderson, 2009). Accordingly, these transformations brought about an awareness of the contradictions between nations and social groups in Europe and thus called for a more precise comprehension of what constitutes European citizenship, especially considering the expansion eastwards after the collapse of the former communist zone - a Union now stretching from Limerick to Nicosia. Without dwelling further on various symbols and initiatives of identification within the realm of the Union such as the monetary system, the Maastricht Treaty witnessed culture for the first time being accorded an advanced position. From this, culture has now evolved to become a defining trait of a European identity: 'Culture binds us together', said the President of the European Commission, José Manuel Barroso, 'as Europeans' (cited in Gordon, 2007, p. 16). The effects of the shift towards culture as a trait of identification have been analyzed by various scholars in a range of topics, disciplines and theoretical traditions. To mention a few: Citizenship (Hansen, 2000a; Martiniello, 1995); the Bologna Process (Fejes, 2008; Kladis, 2003); Higher Education (Hansen, 1997; Johansson, 2007); and Social Policy (Hantrais, 1997). Likewise, the body of research on intercultural dialogue encompasses an array of genres although not directly related to either Europe or the EU. A few of the numerous themes include personal reflections (Finno, 2007); the role of education in developing an intercultural dialogue at various school levels (Fischmann, 2005; Martins, 2008) and as a source of national or regional identification (Petkova, 2006). Here, however, the task is to scrutinize the politics of cultural identity as an element of intercultural dialogue, which is also 
important in relation to, in line with the objectives of the Union, equal identificational possibilities for all citizens and the values that the educational systems are set to transfer. Given this picture, the theoretical framework draws attention to how discourses are produced to provide the inhabitants of a given space with a common identity, which needs to come across as determined, historical and unproblematic.

\section{The (un)making of Europe and non-Europe}

Human communities are 'man made', denoting that the concept of modern society is an artifact and becomes the site of, to reword Bhabha (1994, p. 200), 'writing the nation', despite its claims of being the opposite of constructed - so 'natural' as only requiring self-assertion. Attaching to a previous example used, although nobody would deny the modern concepts of Italy or Italians - or for that matter, Europe and Europeans - these very notions encompass an invented component: communities are constructs of fairly recent vintage, consisting of discourses tailored for a particular purpose such as 'national' history - following the organizational principles of nationalism: one territory, one nation, one people, one language, one culture (Anderson, 2006; Hobsbawm, 1983). Within such processes, cultural references of the past are appropriated into symbols of the present, creating ambivalent temporalities of the space constituting the nation. This is done in a two-folded way, argues Bhabha (1994), with tension between the levels of pedagogy and performativity. On the pedagogical level, the origin of the nation-space is projected as a homogenous one, with the people as an a priori historical existence. Here, all threads in an extended process are intertwined, filling the identity of the nation and its population - the spiritual essence of a collective fantasy - with cultural significance such as shared history, common language, joint values, etc. The objective is to authenticate the inside of space towards the outside: the population as primordial, selected and unique of its kind, negating the population's diversity. Consequently, of equal importance in narrating history is memory, or rather the lack of it: suggestively echoing Renan's (1939[1882]) account of how every national identity requires that history is either forgotten or falsified to maintain the illusion of the past as a harmonious entity - the unisonant temporal link from Ancient Greece to the fall of Soviet rule. Against this background, history schoolbooks may serve an illustrative purpose of the pedagogical approach: descriptions of land and its 'people' being historically and unquestionably interlinked with each other - this is the people of Europe.

While there are historic or other continuities embedded in the name of the community constructed, they rest on exercises of social engineering which are always deliberate. Through these exercises of repeating social practices, sets of conventions and routines are developed and formalized with the purpose of imparting the practice to new practitioners (Hobsbawm, 1983). Performativity, then, articulates the process of how the space is constantly reinvented, its creative moment in the present, while the 'people' are constructed in the discourses. It is the 'scraps, patches, and rags of daily life that must be repeatedly turned into the signs of national culture' (Bhabha, 1994, p. 209). Performativity refers, thus, to the constant reinvention of the 'people' through their everyday lives in terms of producing, acting, living, etc., equally in relation to, but not exclusively dependent on, historical inventions such as flags, images, anthems, holidays. Cultural and national identities are thereby a matter of becoming as well as being, belonging to the past as much as the present and the future. The national identity must always come across as 'original' and 'natural' when totalizing the population of the space. Therefore, as Bhabha (1994, p. 208) puts it, the national ideology roams insecurely between the two levels seeking to legitimize the present through the past, questing for credibility by referring to nations' daily 'natural' and 'prodigious' rebirth - we are Europeans. 
Here, pedagogy and performativity will serve as analytical tools for how the 'European' and the counterpart are constructed when critically examining official EU documents on intercultural dialogue. Policy documents do not tell us how it actually is in 'life', but they do describe the visions and the ideas for the future at the level of the EU and, as an extension, the member states. In addition, with the policy areas of education, citizenship and culture given priority in the Maastricht Treaty as key domains for the schooling of a cohesive 'European identity' (Hansen, 2000b), these documents describe the plans of the EU, from its supranational position of power, to pursue this. Positioned immediately before the article on culture in the Maastricht Treaty, are Articles 126 and 127 on education, which is now further emphasized in relation to intercultural dialogue. Intercultural dialogue is claimed to 'foster the role of education as an important medium for teaching about diversity, increase the understanding of other cultures' and 'European citizens, and all those living in the EU temporarily or permanently, and should therefore have the opportunity to take part in intercultural dialogue and fulfill their potential in a diverse, pluralist, solidarity-based and dynamic society, not only in Europe but also in the world' (EU, 2006, p. 1-3). Within this discursive context that is policies, statements on, for example, a multicultural Europe based on binary opposites with legitimate citizens in one corner and migrants in another, is not restricted to simply implying a discernment of the phenomenon per se, instead it must be analyzed as being bound up with a specific perception of the nation-state and the subjects populating the space (cf. Laclau \& Mouffe, 1987); who belongs there and who does not again, the disjunction between 'Us' and 'Them'. Thus, such statements are caught up in an act between inclusion and exclusion; a reciprocal action of what is being said and what is not. In conjunction with this, how the counterparts are constructed in selected policy documents through the reasons laid out by the EU to promote and endorse an intercultural dialogue are the basis of my readings. In line with the theoretical perspective, the question posed to the materials is the locus of enunciation: who is included vis-à-vis excluded from the levels of pedagogy (this is Europe) and performativity (we are Europe) in statements on intercultural dialogue. The documents analyzed are specifically assigned to intercultural dialogue, education or as responses to the idea of European culture: On a European Agenda for Culture in a Globalizing World [EC, 2007], White Paper on Education and Training [EC, 1995], Sibiu declaration on Intercultural Dialogue and Communicating the European Idea [CE, 2007] and White Paper on Intercultural Dialogue [CE, 2008]. The last two are from the Council of Europe, a policy body I have sought to include to broaden the discourse. It should be noted that not only do the EU and the Council of Europe act under the same flag, their close role as cooperative partners in the cultural sphere is formalized in the Maastricht Treaty [EC, 1992]. To illustrate this even further, a result of this collaboration is the 'European Year of Intercultural Dialogue' in 2008, a point of reference for both the EU and the Council of Europe in their policy making as regards intercultural dialogue.

My readings are conducted with the aim of systematically exploring the factors of what, why, how, where and who as provided in relation to intercultural dialogue by the bodies. Against this background, I have divided the analysis into three parts where the first part aims to investigate the question of what is Europe and who is European as produced in abovementioned documents; the second concerns the reasons for why an intercultural dialogue is required; last and foremost, the third part focuses on how and where the dialogue should be put into use.

\section{Standing on the shoulders of giants: the EU as the inheritor of European history}

Beginning with how European subjects may be constructed through performative and 
pedagogical references on what constitutes the culture of the geo-territory, an effect of such a process is how a dividing line can be drawn to distinguish a 'true' European from another not considered as such. Although it might be wearisome to come to terms with what and who is European, it has already been dismantled how the EU made an attempt with the Maastricht Treaty to infuse culture as a common denominator for the member states by proclaiming improved 'knowledge and dissemination of the culture and history of the European people' and the pedagogical scope of 'safeguarding of cultural heritage of European significance' (EC, 1992, p. 30). Influenced by the treaty, the argument is upheld in recent policy on intercultural dialogue by the Commission.

The originality and success of the European Union is in its ability to respect Member States' varied and intertwined history, languages and cultures, while forging common understanding and rules which have guaranteed peace, stability, prosperity and solidarity - and with them, a huge richness of cultural heritage and creativity to which successive enlargements have added more and more. Through this unity in diversity, respect for cultural and linguistic diversity and promotion of a common cultural heritage lies at the very heart of the European project (EC, 2007, p. 2).

Aside from the merely rhetorical, the text limits the diversity to a compromised number of terms that 'unite' and 'divide', respectively. The subjects created are flexible enough to stand on two legs: both European and citizen of a Member State - an expression that, on the one hand, portrays 'national cultures' as stable unities with a 'pure' content; on the other, illustrate a paradox of how difference and commonality are two sides of the same coin. Worth mentioning is, however, that statements on difference are not always of a dividing and antagonistic character, put forward here is the encapsulation of a difference that is destined to exist side by side in a pluralistic concord - seeking 'harmony, not hegemony' as the president of the Commission, Romano Prodi, put it (cited in Rifkin, 2004, p. 382). As in the quotation above, phrasings in past tense have limitations in what can be stated about the present and, consequently, according to the Commission, 'cultural difference' is restricted to the members of the union having different national cultures, while all coming together under the umbrella term of 'Europe' - the same tree and roots, but different branches. In this story, reliance is not on unity in diversity as alleged above; rather it is diversity from unity, the construction of a framework where diversity becomes a unifying force. Excluded then, however, are those regarded as too culturally different to be included in either a national or the commonality of European culture. Instead 'they' serve the risk of being turned into physical reminders of what 'We' are not. In such performativity of the community, historical sites of struggle and antagonism are negated; for example, colonialism is then embedded in - and reduced to - the phrased 'successive enlargements'.

As the quotation above clearly indicates, the identities of today are attached to historical events; it is through symbolic values and perceptions of the past that generate what 'We' have now. Through these pedagogical narrations, the diversity of Europe is exposed as a common achievement of us all, the performativity of the 'We' as heroic by its ability to reflect peace, solidarity and prosperity that constitute the 'huge richness' in terms of culture that Europeans allegedly share. Speaking in a more clear-cut vernacular, the Maastricht Treaty gives a detailed picture of what could be located behind the grand wording:

European civilisation has a long history and is very complex. It is today divided between a deep thirst for research and knowledge, the legacy of a tradition which made Europe the first to bring about a technical and industrial revolution and thus change the world (EC, 1995, p. 53).

Firstly, to be remarked on is the relationship between the EU and Europe, seen in pedagogical articulation of the EU's genealogical ties with the history of the continent - the roots of Europe are to be regarded as the roots of the Union. An appropriation of the acclaimed past 
where specific moments and symbols are evoked to suit a particular purpose; in this case, to give the EU legitimacy as the present and rightful inheritor of Europe's past. In this semantic achievement, as underlined by Anderson (2009), the term 'Europe' has come to refer simply to the EU, as if the two were interchangeable. Support for such conclusions also comes from when new membership applications are being evaluated. For instance, part of the conclusions of Sweden's submission in 1992 was: holds an 'important place in European history and culture' (EC, 1992, p. 20). More recently, the European Cultural Parliament declared that culture provides an arena necessary for 'the shared values that so deeply bind us in the space called Europe' (CE, 2007, p. 6). Consequently, being a citizen of the EU is to be part of Europe; being part of Europe is, implicitly, to be a citizen of the EU. As phrased above, the subjects attachment to the space is exclusive in the sense that Europe, as it is being articulated, qualitatively changed the world through its, for instance, knowledge production, which brought about an internal shift in the methods of manufacturing - therefore, unique civilization. Nonetheless, while ascribing science and progress as European characteristics, a side effect of such articulation is a stated superiority of Europe over other entities in terms of traits such as knowledge and understanding - also the major premises of Eurocentrism. From such pedagogical narrations, Europe's past is described as something quarantined, independent of any encounter with the surrounding world, beyond political influences and isolated from diasporas, whereas performativity risks of excluding subjects not able to fully relate to such narrow and fixed perception of history. To illustrate this, if we take one of the inventions that the quotation denotes - for instance, the printing press, scrutiny of such a material object that came to symbolize the advent of modernity in Europe would unveil that it already existed in China, pinpointing Said's (1994) reflection of how the history of all cultures is equally the history of cultural borrowings - never about ownership. Only by negating influences from other regions and generalizing its own history and cultural norms, could Europe constitute its superiority in relation to other regions - a Eurocentric ideal that is performatively reappropriated.

From this moment emerges an intricate paradox: if the pedagogical narrative of the EU places itself in the midst of European history and, subsequently, embraces democracy, humanism and industrialization as part of its legacy, equivalently to be interpolated, albeit negated by pedagogy, are colonialism, fascism and slavery. Despite the assertion that the Union was 'founded on norms and values such as human dignity [...] and intercultural dialogue, values which, provided they are upheld and promoted, can be of inspiration for the world of tomorrow' (EC, 2007, p. 3), at the time of its founding four of the six member states had colonies, and Spain and France have yet to complete the decolonization process. ${ }^{1}$ With reference to this, the question of why emerges; why is an intercultural dialogue a necessity at the present time and between whom? Staying within the Commission's framework of European culture, the motives, as laid out by the EU, for engaging in an intercultural dialogue and its performativity will be unfolded below.

\section{The (un)desirable melting pot - EUropean reasons for intercultural dialogue}

Through the question of why an intercultural dialogue has been given a central position in policies on culture and education, I will demonstrate how the ideas of originality and alteration operate within the discourses on intercultural dialogue: how subjects are inscribed or outscribed from a particular community and the justification for this performative action. As pointed out by others (cf. Gundara, 2000; Jones, 1999), the widespread recognition of racial multiplicity in the West has led to increased calls for bridging cultures through dialogue - sharing and talking across cultural and ethnical dividing lines. The same argument can be 
found in documents from the Commission while seeking to explain why intercultural dialogue is essential for the present wellbeing of all.

In recent decades, cultural diversification has gained momentum. Europe has attracted migrants in search of a better life and asylum-seekers from across the world. [...] As we live in increasingly multicultural societies, we need therefore to promote intercultural dialogue and intercultural competences (EC, 2007, pp. 8-13).

Within the locution of the Commission, intercultural dialogue can be perceived as a way of living inside its borders, of living with difference, living with proximity to strangers. The reasons, however, to the growing emphasis on intercultural dialogue at this given moment seems to be that people from other parts of the world are now occupying a space inside the borders of the continent. Within the line of logic as hinted above, 'cultural diversification' is the outcome of 'migrants' and 'asylum-seekers' residing within the Union. On the one hand, such a stand presupposes the existence of something explicitly 'European', a purity long gone missing in the heterogeneous melting pot that the space has been turned into, due to the contemporary existence of diverse ethnicities, religions and languages; on the other, there is thus a strong case here for arguing that without the existence of 'migrants' intercultural dialogue would have been redundant. Nonetheless, in critically assessing the Commission's formulations, the intention is not to downgrade the existence of migration or demographic displacements per se, rather to illustrate how such statements are bound up with a specific perception of the member states as an account appealing 'to a pure and settled past' (Bhabha, 1989, p. 39). Within such process, the subjectification of the Other is done beyond the borders of European civilization, ignored by pedagogy and excluded through performativity, only graspable, as explained by Bhabha (1994, p. 217), between 'here' and 'somewhere else' 'here' while explaining Europe's multicultural present, 'somewhere else' in pedagogical references to what is Europe.

This double scenery works in favor of an absolute negation of common values or characteristics; the Other becomes the dualistic opposite of the European, only present when being talked about or told. Further evidently, in the case of the Council of Europe, in the actual definitions of the basic conditions for an intercultural dialogue: 'Immigrants should, as everybody else, abide by the laws and respect the basic values of European societies and their cultural heritage' (CE, 2008, p. 11). In this performativity of Europe, 'immigrants' are construed as neither Europeans nor part of European history and culture, possibly possessors of characteristics conflicting with the rules and values of Europe. Thus, what is then required of the Other is that its difference, its generating of diversity, fits into a normative model of what the Europe and the Europeans are in the eyes of the EU. Yet, in spite of this, the efforts may be in vain:

However, pluralism, tolerance and broadmindedness may not be sufficient: a pro-active, a structured and widely shared effort in managing cultural diversity is needed. Intercultural dialogue is a major tool to achieve this aim, without which it will be difficult to safeguard the freedom and well-being of everyone living on our continent. [...] The universal values upheld by the Council of Europe are a condition for intercultural dialogue. No dialogue can take place in absence of respect for the equal dignity of all human beings, human rights, the rule of law and democratic principles (CE, 2008, p. 16).

In focus, then, are the dual sceneries of, on the one hand, the potential risks of a non-dialogue; on the other, why it is only in the hands of the Council of Europe that we can truly entrust the conditions for an intercultural dialogue. Being put forward is the visualization of how intercultural dialogue is not an option; it is a must - an imperative demanding obedience and action. Action in the sense of avoiding quarrels and maintaining social safety; obedience to uphold human rights and democracy. Inscribed in the rhetoric above for an intercultural dialogue is the referring to the future, a strategy that delegitimizes opposition towards the 
political body in question and the hypothetical in not finding intercultural dialogue compelling, a stand which would be regarded as undemocratic and dangerous since it then opposes the common universal and democratic desires of humanity. The future tense calls upon history to favor the present: the 'We' needed to engage in intercultural dialogue to safeguard social cohesion, 'Our' historic values and common destination, by which everyone living within the frontiers of the Union will eventually - including 'immigrants' - be able to take part of the ideals that Europe gave raise to. Hereby emerges intercultural dialogue as a resource to neutralize doctrines conflicting with 'European values', stipulating a plea to the Union to come to the rescue of equally the people living inside the Union as outside of it: 'The breakdown of dialogue within and between societies can provide, in certain cases, a climate conducive to the emergence, and the exploitation by some, of extremism and indeed terrorism. Intercultural dialogue, even on the international plane, is indispensable between neighbours' (CE, 2008, p. 16). Any threat of not desiring dialogue is then a direct threat against the idea of the Union and its position as protector of humanity; a discourse gaining legitimacy by proclaiming certain ascribed values tied to Europe as universal. What unfold are the central traits of a Eurocentric worldview, which, argues Anderson (2009), characterize the EU of today: presented as a paragon for the rest of the world, the Union asserts itself to embody a higher set of values than other regions. Bearing this in mind, attention below will be drawn towards where and how intercultural dialogue shall take place.

\section{Spreading the word - the monolingualism of the dialogue}

Although it seems clear to argue that the EU embraces the history of the continent and regards itself as a natural inheritor of Europe's legacy, left out from these pedagogical narratives are less prideful ones - aspects incompatible with dignity, equality and democracy. With a focus on the more concrete motives as provided by the EU for the practices of where to apply intercultural dialogue and how it should be conducted, a strong case can be made that the outcomes of, for instance, colonialism are conjured into pragmatic solutions of the present in contact with the outside of Europe, while negating how they emerged and its costs. In promoting intercultural dialogue, reasons for invoking culture as an important aspect of the international relations are formulated by the EU as follows:

The Community and the Member States have reaffirmed their commitment to developing a new and more proactive cultural role for Europe in the context of Europe's international relations and to integrating the cultural dimension as a vital element in Europe's dealing with partner countries and regions. This should help promoting knowledge of and understanding for Europe's cultures throughout the world (EC, 2007, p. 10).

On the whole, the quotation makes lofty assertions such as 'Europe's culture' and how elements embedded in this specific type of culture are to be inserted as a vital dimension in contact with the surrounding world. With the objective phrased as to promote 'knowledge' and 'understanding', intercultural dialogue is not restricted to being a communicative bridge between citizens and 'immigrants' residing on the continent, but equally as a teaching machine of European culture to other regions. According to the Commission, such an initiative is acting upon the requests of its citizens: 'Recent opinion polls clearly show that, under the pressure of globalization, the great majority of Europe's citizens [...] want Europe to be more present in the world, with an external policy that which well reflects its values' (EC, 2007, pp. 3-7). This, on the one hand, negates the possibility of other desires to be "more present in the world', a performative operation of the Union - as a protector of universal values, guaranteeing peace and stability on the international scene - taking its moral responsibility. On the other, the quotation brings raise to the returning question of what is embedded in the 'values' that Europe allegedly reflects. Moving closer to the social terrain, 
the Commission adds another characteristic to the previous group of, for instance, human rights, democracy and the rule of law by emphasizing the existence of multifaceted languages: They [the Member States] also enjoy and value a rich cultural and linguistic diversity, which is inspiring and has inspired many countries across the world (EC, 2007, p. 2). At stake in this act is the ability to take pride in the outcomes of an event with a horrible downside. As can be seen, the quotation illustrates a pedagogical avoidance of mentioning how and in what ways Europe 'inspired' other regions culturally and language wise. The effects of these 'inspirations' can be located already at the level of name, spaces that in terms of classification symbolized inherency and dependence - 'British' Virgin Islands, América 'Latina', l'Algérie 'Française'.

The pedagogical narratives offered by the EU are then contradictory. While positioning itself as the inheritor of Europe's legacy, articulated is a dubious and highly selective pedagogical version of Europe's historical relations, civilization and heritage. This is being brought to a head by the Commission in descriptions on how to practically engage in intercultural dialogue: 'It is crucial to develop active inter-cultural dialogue with all countries and all regions, taking advantage of for example of Europe's language links with many countries' (EC, 2007, p.10). As hinted at above, Europe's language links with other regions are products of colonialism, since without the colonial enterprise these language links would not have existed. On a side note, this may confirm the critique put forward by scholars from Eastern Europe of how the cultural features within the EU are utterly Western (Kovács \& Leipnik, 2008), since the sources of language links mentioned - and thus the colonial powers - are located in the West. It is important to bear in mind that control over language was one of the main features of colonial oppression. Once under European rule, the authorities installed replicas of their systems for education, administration and governance. By doing exactly this, a 'pure' idiom could replace the 'impurities' and 'degenerated offshoots' spoken in the newly colonized space, a forced change altering the incarnation of words among the repressed. A word, a term or an expression does not have the same meaning or interpretation in different languages and contexts. Although the intention might lie elsewhere, the basic sentiment of the phrasing above is that the language of intercultural dialogue is in accordance with that of the former authorities. Such performative construction transforms the very residues of colonialism into a convenient possibility. The metropolitan languages of Europe spread their linguistic tentacles via colonial endeavors, and the very languages are now recycled as the lingua franca of intercultural dialogue. For instance, the author Salman Rushdie (1991) points out that Indian-English writers cannot use their language in the same direct sense as a Brit when narrating Indian themes in English, they need to be modified, adapted, revised, to suit the linguistic apparatus and figures of speech of the former colonizer. Dialogue through European languages would then reassert Europe's privileged position in relation to other regions; territories subjected to the requirements to speak, write and think in the language of the of the former authorities - thus revealing once again the paradoxical nature of European supranational bodies' self-reflection and the limited reliability in the talk about intercultural dialogue as the 'guarantee of non-domination' (CE, 2008, p. 19).

\section{Conclusions}

What I have attempted to show here is that intercultural dialogue, as articulated by the EU, can become a tool of exclusion that ends up reifying differences equally as in line with its articulated purpose of being an inclusionary mutual bridge between individuals and cultures. As a result, I have outlined how the EU, in an attempt to construct a cultural 'We', identifies itself with the history of the continent: Europe is portrayed as a homogenous unit, a continuous order, the successor of the Greco-Roman legacy. Historical events, figures of 
thought and sceneries are appropriated to provide the EU with historical authority with its citizens as an organized singularity. Hence, the method applied by the EU is recreation and rebirth of what is desired, a selective perspective of Europe's historical past that can be interpreted as accumulating everything undesired by means of performativity; wars and blood, genocide and imperialism - seemingly a technique for forgetting its dark side in order to claim the universalizable nature of its declared good side (Hall, 1997). A dividing line is drawn on both the pedagogical and the performative level between the European subject and the one not considered as such - the 'We' and 'Them' in the dialogue. Pedagogy ignores the Other in descriptions of what constitutes Europe, and the subjectification of the Other by performativity is as a binary opposite of the European. Following this analogy, subjects not considered as Europeans serve as markers of the multicultural present of the space. As far as the analysis conducted here is concerned, a true European is the one who is not like the one who is not.

In a broader sense, the educational systems of the Member States risks partly fuelling such a process by emphasizing, as in the case of Sweden, the importance of embracing 'European values' and that schools should develop such an identity among the students; strengthening the knowledge of their cultural heritage (Lpf 94). The conclusions drawn are in line with the suggestions of other scholars (cf. Dainotto, 2007; Spivak, 2004) that Eurocentric and colonial ideas continue to shape teaching and curricula, which may implicate that intercultural education - and other educational practices emphasized by the EU - becomes tools of exclusion rather than creating a bond between subjects residing inside as well as outside the community. In this sense there is thus a strong case for arguing that an intercultural dialogue, as determined by the EU, is only possible when the counterparties in the dialogue share the same cultural contexts or equal balance of power, for instance, between Western European nation-states. And thereby it would seem that intercultural dialogue cannot be accomplished on equal terms as long as both the conditions and the content are dictated by the European Union - rather referring to an intracultural dialogue.

Moreover, the Eurocentric approach to an intercultural dialogue, as this study shows, raises another educational question since it is these settings who are given responsibility for providing its students with intercultural competence (EC, 2008, p. 9): 'Education should promote intercultural skills, democratic values, the respect of fundamental rights and the fight against discrimination'. It should be noted that Donald (1992) underscores that subjects, by means of pedagogy and performativity, are constructed and taught their place in a society through its educational system, simultaneously, a general identification with the community is produced through the imaginary idea of a shared ancestry. Thus, a task left to carry out is to explore how such policies unfold in educational settings, curriculum and, by extension, among the very citizens of the Union.

\section{Notes}

1. Several 'non-European' territories, such as Ceuta, Melilla and French Guyana, are still part of Spain and France, respectively, and thus fully incorporated, on paper, in the EU (Hansen, 2002).

\section{References}

Alred, G, Byrmam, M, \& Fleming, M. (2006) Education for Intercultural Citizenship

(Cromwell, Cromwell Press Ltd).

Anderson, B. (2006) Imagined Communities (London, Verso).

Anderson, P. (2009) The New Old World (London, Verso).

Bhabha, H. K. (1989) Down among the writers, New Statesman \& Society, 28 July.

Bhabha, H. K. (1994) The Location of Culture (London, Routledge). 
Council of Europe. (2008) Living together as equals in dignity (White Paper on Intercultural Dialogue) (Strasbourg, CE).

Council of the European Communities. (1992) The Maastricht Treaty (Luxemburg, Office for Official Publications of the EC).

Dahlén, T. (1997) Among the Interculturalistas: An Emergent Profession and its Packaging of Knowledge (Stockholm, Gotab).

Dainotto, R. (2007) Europe (In Theory) (Durham, Duke University Press).

Dewey, P. (2008) Transnational Cultural Policymaking in the European Union, The Journal of Arts Management, Law, and Society, 38:2, pp. 99-118.

Donald, J. (1992) Sentimental Education (London, Verso).

European Commission. (1992) The challenge of enlargement: Commission opinion on Sweden's application for membership, in: Bulletin of the European Communities (CVCE).

European Commission. (1995) Teaching and Learning: towards the learning society (White Paper on Education and Training) (Brussels, EC).

European Commission. (2001) Communication from the Commission: Making a European Area of Lifelong Learning a Reality (Brussels, EC).

European Commission. (2007) Communication from the Commission: A European Agenda for Culture in a Globalizing World (Brussels, EC).

European Commission. (2008) Communication from the Commission: An updated strategic framework for European cooperation in education and training (Brussels, EC).

European Commission. (2009) Council conclusions of 12 May 2009 on a strategic framework for European cooperation in education and training (Brussels, EC).

European Cultural Parliament. (2007) Sibu declaration on Intercultural Dialogue and Communicating the European Idea (Sibu, CE).

European Union. (2006) Decision No. 1983/2006/EC concerning the European year of Intercultural Dialogue, 18 December, Official Journal of the European Union.

Fejes, A. (2008) European Citizens under Construction: The Bologna Process Analysed from a Governmentality Perspective, Educational Philosophy and Theory, 40:4, pp. 515-530.

Finno, M. (2007) The Intercultural Dialogue: A Personal Reflection on the Migrant Experience and the Effects of Latin American Migration to the U.S., Journal of Poverty, 11:2, pp. 117-128.

Fischmann, R. (2005) Historical and Legal Remarks on Cultural Diversity and Higher Education in Brazil in the Context of the School System, Higher Education Policy, 18:4, pp. 375-395.

Gordon, C. (2007) Culture and the European Union in a Global Context, The Journal of Arts Management, Law, and Society, 37:1, pp. 11-26.

Gundara, J. (2000) Interculturalism, Education and Inclusion (London, Paul Chapman Publishing Ltd).

Hall, S. (1997) The West and the Rest: Discourse and Power, in: S. Hall et al (ed.) Modernity: An introduction to Modern Societies (Oxford, Blackwell Publishers Ltd.).

Hansen, P. (1997) Education in a multicultural European Union: between intercultural visions and a realpolitik of immigration, Migration: A European Journal of International Migration and Ethnic Relations, 32, pp. 5-40.

Hansen, P. (2000a) Europeans only? Essays on identity politics and the European Union (Umeå, Umeå University Printing Office). 
Hansen, P. (2000b) The cultural short cut, a road to exclusion? Notes on identity politics in the European Union, in: J. Gundara \& S. Jacobs (eds.) Intercultural Europe: Diversity and Social Policy (Aldershot, Ashgate).

Hantrais, L. (1997) Exploring Relationships between Social Policy and Changing Family Forms within the European Union, European Journal of Population, 13:4, pp. 339-379.

Hobsbawm, E. (1983) Introduction: Inventing Traditions, in: E. Hobsbawm \& T. Ranger (eds.) The Invention of Tradition (Cambridge, Cambridge University Press).

Hogan, L. (2004) Tapping (into) Reality: Encounters between Pinocchio and the phenomenon of reality TV, Quaderni D'Italianistica, 25:1, pp. 71-93.

Johansson, J. (2007) Learning To Be(come) A Good European (Linköping, LiU-Tryck).

Jones, A. (1999) The limits of Cross-Cultural Dialogue: Pedagogy, Desire and Absolution in the Classroom, Educational Theory, 49:3, pp. 299-316.

Kladis, D. (2003) The Social Dimension of the Bologna Process, Higher Education in Europe, 28, pp. 353-354.

Kovác, M. \& Leipnik, O. (2008) The Border of Orientalism: 'Europeanization' in Hungary and Ukraine, Debatte, 16:2, pp. 151-169.

Laclau, E. \& Mouffe, C. (1987) Hegemony and Socialist Strategy (London, Verso).

Martiniello, M. (1995) Migration, citizenship and ethno-national identities in the European Union (Aldershot, Avebury).

Martins, I. (2008) Learning to Live Together: the contribution of intercultural education, European Journal of Education, 43:2, pp. 197-206.

Mignolo, W. (2006) Citizenship, Knowledge and the Limits of Humanity, American Literary History, 18:2, pp. 312-331.

Osler, A. \& Starkey, H. (2002) Education for Citizenship: mainstreaming the fight against racism?, European Journal of Education, 37:2, pp. 143-159.

Petkova, D. (2006) National images and intercultural dialogue in Southeast Europe, Organisational transformation and social change, 3:2, pp. 135-155.

Renan, E. (1939[1882]) What is a Nation?, in A. Zimmern (ed.) Modern Political Doctrines (London, Oxford University Press).

Rifkin, J. (2004) The European Dream: How Europe's Vision of the Future is Quietly Eclipsing the American Dream (Oxford, Polity).

Rushdie, S. (1991) Imaginary Homelands (London, Granta).

Said, E. W. (1994) Culture \& Imperialism (London, Vintage)

Spivak, G-C. (2004) Righting Wrongs, South Atlantic Quarterly, 103:2-3, pp. 523-581.

Swedish National Agency for Education (1994) Curriculum for the non-compulsory school system - Lpf 94 (Stockholm, Fritzes).

Weaver, M. (2010) Angela Merkel: German multiculturalism has utterly failed, The Guardian, 17 October.

Wimberley, J. (2003) Education for intercultural and interfaith dialogue: A new initiative by the Council of Europe, Prospects, 33: 2, pp. 199-209. 